Supporting Information for

\title{
Graphite-Conjugation of a Macrocyclic Cobalt Complex Enhances Nitrite Electroreduction to Ammonia
}

\author{
Sarah E. Braley, ${ }^{\dagger}$ Jiaze Xie, ${ }^{\ddagger}$ Yaroslav Losovyj, ${ }^{\dagger}$ Jeremy M. Smith ${ }^{*+}$
}




\section{Table of Contents}

Experimental Section S4

Preparation of graphite-conjugated catalysts S5

X-Ray Photoelectron Spectroscopy (XPS)___ S6

Quantification of Bromide __ S7

X-Ray Absorption Spectroscopy (XAS)___ S8

Surface Coverage Determination __ S9

Tafel Data Collection __ S9

Calculation of Faradaic Efficiency ___ S9

Electrochemical Data __ S11

Figure S1: Cyclic voltammogram of GCC-CoDIM (glassy carbon) recorded in $0.5 \mathrm{M} \mathrm{Na}_{2} \mathrm{SO}_{4}$, scan rate $100 \mathrm{mV} / \mathrm{s}$. Inset: Plot of $i_{\mathrm{p}, \mathrm{c}} v s . v$ and the best fit. The plot fits to the equation: $\mathrm{y}=$ $0.0165 \mathrm{x}+5.513 \times 10^{-4}, \mathrm{R}^{2}=0.999$.

Figure S2: Cyclic voltammogram of CoDIM-FG (flexible graphite) recorded in $0.1 \mathrm{M} \mathrm{KBr}$, scan rate $100 \mathrm{mV} / \mathrm{s}$. Area of integration $=5.19 \times 10^{-4} \mathrm{C}$. Red shows area of integration._ S11

Figure S3: Cyclic voltammogram of GCC-CoDIM (glassy carbon) recorded in $0.5 \mathrm{M} \mathrm{Na}_{2} \mathrm{SO}_{4}$, scan rate $100 \mathrm{mV} / \mathrm{s}$. Area of integration $=3.92 \times 10^{-6} \mathrm{C}$. Red shows area of integration.__ S12

Figure S4: Cyclic voltammogram of two independently prepared GCC-CoDIM (glassy carbon) recorded in $0.5 \mathrm{M} \mathrm{Na}_{2} \mathrm{SO}_{4}$ with $40 \mathrm{mM} \mathrm{NaNO}_{2}$, scan rate $100 \mathrm{mV} / \mathrm{s}$.

Figure S5: Cyclic voltammograms of GCC-CoDIM (glassy carbon) (red) and oxidized GC (black) recorded in $0.5 \mathrm{M} \mathrm{Na}_{2} \mathrm{SO}_{4}$ with $40 \mathrm{mM} \mathrm{NaNO}_{2}$, scan rate $100 \mathrm{mV} / \mathrm{s}$.

Figure S6: Cyclic voltammograms of GCC-CoDIM (glassy carbon) (red) and oxidized GC soaked in $\mathrm{CoBr}_{2} \cdot 6 \mathrm{H}_{2} \mathrm{O}$ /methanol solution (black) recorded in $0.5 \mathrm{M} \mathrm{Na}_{2} \mathrm{SO}_{4}$ with $40 \mathrm{mM}$ $\mathrm{NaNO}_{2}$, scan rate $100 \mathrm{mV} / \mathrm{s}$.

Figure S7: Charge passed during CPE with CoDIM-FG (black) or oxidized FG prefunctionalization (red) in $0.5 \mathrm{M} \mathrm{Na}_{2} \mathrm{SO}_{4}$ with $20 \mathrm{mM} \mathrm{NaNO}_{2}$ for 2 hours at $-1.4 \mathrm{~V} v$ s. SCE.

Figure S8: Cyclic voltammogram of GCC-CoDIM (glassy carbon) recorded in $0.5 \mathrm{M} \mathrm{Na}_{2} \mathrm{SO}_{4}$ with $20 \mathrm{mM} \mathrm{NaNO}_{2}$ at pH 5.7 (black), pH 8.5 (red), and pH 11.1 (blue), scan rate $100 \mathrm{mV} / \mathrm{s}$.

Figure 9: Normalized K-edge X-ray absorption near edge structure spectrum of CoDIM-

functionalized Monarch Carbon Powder. S15

Figure S10: Crystal structure of $\left[\mathrm{Co}(\mathrm{DIM}) \mathrm{Br}_{2}\right]^{+}$with atom labels. ${ }^{9}$ S 15

Table S1: EXAFS Fit Parameters for CoDIM-functionalized Monarch Carbon Powder. S15 
Table S2: Comparison of EXAFS, single crystal XRD, and DFT-calculated bond lengths. S16 Figure S11: EXAFS spectrum (black) and fit (red) in R-space at the Co K-edge absorption of CoDIM-functionalized Monarch Carbon Powder. S16

Figure S12: EXAFS spectrum (black) and fit (red) in k-space at the Co K-edge absorption of CoDIM-functionalized Monarch Carbon Powder. S17

X-Ray Photoelectron Spectroscopy Data S18

Table S3: Surface atomic concentrations determined from XPS. $\mathrm{S} 18$

Table S4: Relative surface atomic concentrations of $\mathrm{Co}, \mathrm{N}, \mathrm{Br}$, and $\mathrm{Cl}$ in GCC-CoDIM determined from XPS.

Table S5: Relative surface atomic concentrations of $\mathrm{Co}$ and $\mathrm{Br}$ in GCC-CoDIM after variable time under ultra-high vacuum determined from XPS.

Figure S13: High-resolution Co 2p XPS spectrum of freshly prepared GCC-CoDIM (glassy carbon). The measured signal is in black, the overall fit manifold in blue, and the fit peaks in blue and purple.

Figure S14: High-resolution N 1s XPS spectra of freshly prepared GCC-CoDIM (top) and GCC-CoDIM after a soak in $\mathrm{pH} 13 \mathrm{NaOH}$ solution (bottom). The measured signal is in black, the fit background in dashed red, the fit peaks in green, orange, and red, and the overall fit manifold in blue. S20

Figure S15: High-resolution Co 2p XPS spectrum of CoDIM-FG after $2 \mathrm{~h}$ bulk electrolysis at $-1.4 \mathrm{~V} v$ s. SCE. The measured signal is in black, the overall fit manifold in red, and the fit peaks in blue and green.

Figure S16: a) High-resolution Co 2p XPS spectra of freshly prepared GCC-CoDIM (black), an oxidized glassy carbon electrode (blue), and a polished glassy carbon electrode (red). b) High-resolution N 1s XPS spectra of freshly prepared GCC-CoDIM (black), an oxidized glassy carbon electrode (blue), and a polished glassy carbon electrode (red).

Figure S17: High-resolution Cl 2p XPS spectra of freshly prepared GCC-CoDIM (red) and GCC-CoDIM after soaking 12 hours in $1.0 \mathrm{M} \mathrm{KCl}$ solution. The measured signal is in black, the overall fit manifold in blue, the fit background in dashed red, and the fit peaks in blue and green.

Figure S18: (a) High-resolution N 1s XPS spectra of [Co(DIM)Br 2$] B r$. The measured signal is in black, the fit background in dashed red, the fit peaks in green, orange, and red, and the overall fit manifold in blue. (b) High-resolution Co 2p XPS spectrum of [Co(DIM)Br $\left.\mathrm{Br}_{2}\right] \mathrm{Br}$. The measured signal is in black, the overall fit manifold in blue, and the fit peaks in blue and purple.

Table S6: Peak binding energies from high resolution $N$ 1s and Co $2 p$ XPS data of [Co(DIM)Br 2$] \mathrm{Br}$ and GCC-CoDIM. 


\section{Experimental Section}

General Considerations. All anaerobic manipulations, including non-aqueous electrochemical measurements, were performed under a nitrogen atmosphere using standard Schlenk techniques or in an MBraun Labmaster glovebox. Ultrapure water was used for all aqueous experiments or measurements. All reagents were purchased from commercial venders and used as received. Ammonia, hydroxylamine, and bromide were analyzed according to literature protocols. $.^{1-3} \mathrm{UV}-$ visible spectra were recorded with an Agilent Cary 60 UV-visible spectrometer. pH measurements were performed at $25.0^{\circ} \mathrm{C}$ on a Mettler Toledo $\mathrm{pH}$ meter. The $\mathrm{NaOH}$ solutions for $\mathrm{pH}$ adjustment were freshly prepared using ultrapure water to minimize carbonate formation.

Electrochemical Methods. Electrochemical measurements were recorded at ambient temperature on a CHI 620E electrochemical analyzer (CH Instruments). Cyclic voltammetry experiments were carried out in an argon purged, air-tight, single compartment cell while controlled potential electrolysis (CPE) experiments were carried out in a two-compartment cell with a fine frit separating the working and auxiliary compartments. Unless otherwise stated, current densities were normalized to the geometric surface area of the working electrode. Working electrode: glassy carbon electrode (3 mm diameter, $\mathrm{CH}$ Instruments) for cyclic voltammetry, flexible graphite (Grafoil@) electrode $(1.5 \mathrm{~cm}$ x $2.0 \mathrm{~cm}$ ) for CPE. Auxiliary electrode: platinum wire (Alfa Aesar, 99.99\%). Pseudo-reference electrode: Ag wire (Alfa Asear, 99.99\%) for non-aqueous solution and $\mathrm{Ag} / \mathrm{AgCl}(\mathrm{CH}$ Instruments, $1.0 \mathrm{M} \mathrm{KCl},-0.006 \mathrm{~V}$ vs. SCE $)$ for aqueous solution. The reproducibility of all cyclic voltammetry experiments was verified by multiple repeated scans. The solution $\mathrm{pH}$ for aqueous cyclic voltammetry experiments was 6.1 unless otherwise stated. All electrode potentials are plotted $v s$. the standard calomel electrode. Tafel data were collected at ambient temperature on a BioLogic SP-300 potentiostat. 


\section{Preparation of graphite-conjugated catalysts}

Electrode cleaning and pretreatment: Glassy carbon disk electrodes were polished against a Buehler polishing pad with a $0.05 \mu \mathrm{m}$ alumina slurry for two minutes, followed by rinsing with reagent-grade water. To increase the surface area and expose more quinone moieties, glassy carbon disk electrodes were anodized via controlled potential electrolysis at $3.3 \mathrm{~V} v s$. SCE for 10 seconds in $0.1 \mathrm{M} \mathrm{H}_{2} \mathrm{SO}_{4}$ under $\mathrm{Ar}^{4}$ Electrodes were subsequently washed with copious amounts of reagentgrade water and methanol and dried in vacuo prior to electrochemical evaluation.

Flexible graphite electrodes were only functionalized once and were used as received, without polishing. To increase the population of quinone moieties on the surface, these electrodes were anodized via controlled potential electrolysis at $1.6 \mathrm{~V}$ vs. SCE for 120 seconds in $0.1 \mathrm{M}$ $\mathrm{H}_{2} \mathrm{SO}_{4}$ under $\mathrm{Ar}$ and washed with copious amounts of reagent-grade water and methanol prior to functionalization.

Oxidized glassy carbon disk and flexible graphite electrodes were used without any further preparation for background $\mathrm{CPE}$ data collection. Oxidized glassy carbon disk electrodes were stirred in a $10 \mathrm{mM}$ solution of $\mathrm{CoBr}_{2} \cdot 6 \mathrm{H}_{2} \mathrm{O}$ in methanol for 4 hours under argon followed by a 1 hour soak in $0.1 \mathrm{M} \mathrm{HCl}$ to obtain the cyclic voltammetry data in Figure S6.

Preparation of graphite-conjugated [Co(DIM)Br2 $]^{+}$: Surface functionalization was carried out by immersing oxidized graphitic carbon electrodes (flexible graphite and disks) in $\sim 10 \mathrm{~mL}$ methanol. 1,2-Bis(3-aminopropylamino)ethane $(37.1 \mu \mathrm{L}, 0.2 \mathrm{mmol})$ and $48 \%$ aqueous $\mathrm{HBr}(21.9$ $\mu \mathrm{L}$ ) were added, and the solution was stirred for $1 \mathrm{~h}$ at ambient temperature. ${ }^{5}$ The reaction vessel was subsequently purged with Ar. Solid $\mathrm{CoBr}_{2}$ hexahydrate $(32.7 \mathrm{mg}, 0.1 \mathrm{mmol})$ was added under positive Ar flow and the vessel closed, immediately giving a brown solution. The vessel was heated 
under Ar for $12 \mathrm{~h}$ at $50{ }^{\circ} \mathrm{C}$ with stirring, leading to a bright green solution. After $12 \mathrm{~h}$, the vessel was opened, and the solution exposed to air for 30 minutes. After cooling, the solution was decanted, and the electrodes were rinsed with copious amounts of methanol and ultrapure water. The electrodes were then soaked in $0.1 \mathrm{M} \mathrm{HCl}$ for 1 hour to hydrolyze adventitious imine linkages formed on the surface. Following this acid treatment, electrodes were rinsed with water and dried. All characterization, cyclic voltammetry, and XPS data was collected on materials prepared by this procedure. XPS data was also collected after the electrode was soaked for 1 hour in $\mathrm{pH} 13$ $\mathrm{NaOH}$ solution to observe the change in the $\mathrm{N}$ 1s data (Figure S14).

Preparation of Co-Functionalized Monarch Carbon Powder (CoDIM-Monarch): To $55.7 \mu \mathrm{L}$ 1,2-bis(3-aminopropylamino)ethane $(0.3 \mathrm{mmol})$ and $32.9 \mu \mathrm{L} 48 \%$ aqueous $\mathrm{HBr}$ in $15 \mathrm{~mL}$ methanol was added $100 \mathrm{mg}$ CABOT Monarch 1300 Carbon Black. The solution was stirred for $1 \mathrm{~h}$ at ambient temperature, then purged with $\mathrm{Ar}$. $\mathrm{CoBr}_{2}$ hexahydrate $(49.1 \mathrm{mg}, 0.15 \mathrm{mmol})$ was added to the black suspension under positive Ar flow and the vessel closed. The vessel was heated under Ar for $12 \mathrm{~h}$ at $50{ }^{\circ} \mathrm{C}$ with stirring. After $12 \mathrm{~h}$, the vessel was opened, and the solution exposed to air for 30 minutes. The mixture was filtered and rinsed with methanol. The carbon powder was collected and stirred in $10 \mathrm{~mL}$ of aqueous $0.1 \mathrm{M} \mathrm{HCl}$ for $3 \mathrm{~h}$. The aqueous mixture was then filtered and washed with water and methanol. The isolated carbon powder was further washed with hot methanol in a Soxhlet extractor until the washings were colorless. The modified carbon powder was collected and dried in vacuo.

\section{X-Ray Photoelectron Spectroscopy (XPS)}

XPS spectra were recorded for GC, flexible graphite (Grafoil@) electrodes, and Monarch carbon powder. Freshly prepared electrodes were measured with no further treatment beyond their usual preparation described above. X-Ray photoelectron spectra (XPS) were recorded using a Physical 
Electronics PHI Versaprobe II XPS with a hemispherical energy analyzer and a monochromatic aluminum $\mathrm{K}_{\alpha} \mathrm{X}$-ray source $(1486.6 \mathrm{eV})$. The XPS spectra were collected with X-ray power of 25 $\mathrm{W}$ at $15 \mathrm{kV}$ and a 200 micron beam size. Metallic $\mathrm{Au}, \mathrm{Ag}$ and $\mathrm{Cu}$ were used for instrument calibration. The PHI dual charge compensation system was used at all measurements. The ultimate Versaprobe II instrumental resolution was determined to be better than $0.125 \mathrm{eV}$ using the Fermi edge of the valence band for metallic silver. XPS spectra with an energy step of $0.1 \mathrm{eV}$ were recorded using SmartSoft-XPS v2.6.3 at pass energies of $46.95 \mathrm{eV}$ for N 1s, $23.5 \mathrm{eV}$ for C and O 1s, and $93.9 \mathrm{eV}$ for $\mathrm{Co} 2 \mathrm{p}, \mathrm{Br} 3 \mathrm{~d}$, and $\mathrm{Cl} 2 \mathrm{p}$. All peaks were referenced to the $1 \mathrm{~s}$ graphitic carbon peak $(284.4 \mathrm{eV})$ in HOPG. The XPS spectra were processed with PHI MultiPack v9.0 software. Peaks were fitted using GL line shapes, i.e., a combination of Gaussians and Lorentzians with 10$50 \%$ of Lorentzian contents. Shirley background was used for curve-fitting. The sample for XPS was placed on the sample platform using double-sided Scotch tape. Spectral reproducibility over three sample regions showed the reliability of the data.

\section{Quantification of Bromide}

Co-functionalized glassy carbon disk and flexible graphite electrodes were digested with concentrated nitric acid for $10 \mathrm{~min}$ and diluted to a final volume of $50 \mathrm{~mL}$ by addition of ultrapure water. The bromide concentration in the resulting solution was determined via a literature procedure, ${ }^{3}$ allowing the concentration on the electrochemically active surface to be determined. A calibration curve was constructed using the same literature procedure for accurate concentration determination.

Additional bromide was not observed in a subsequent acid digestion of the same electrode. In addition, no bromide was detected from the acid digestion of oxidized glassy carbon electrodes. 


\section{X-Ray Absorption Spectroscopy (XAS)}

A powder sample of CoDIM-functionalized Monarch Carbon Powder was prepared by grinding finely. A Teflon washer (5.3 mm internal diameter) was sealed on one side with Kapton tape and powder was then transferred to the inside of this ring before compacting with a Teflon rod and sealing the remaining face with Kapton tape. The sample preparation was performed under an inert atmosphere. X-ray absorption near-edge spectra (XANES) and Extended Absorption Fine Structure (EXAFS) were employed to probe the local environment around Co. Data were acquired at the Advanced Photon Source at Argonne National Labs with a bending magnet source with ring energy at $7.00 \mathrm{GeV}$. Co K-edge $(7709 \mathrm{eV})$ data were acquired at the MRCAT 10-BM beam line in transmission. The incident, transmitted, and reference X-ray intensities were monitored using gas ionization chambers. A metallic cobalt foil standard was used as a reference for energy calibration and was measured simultaneously with experimental samples. X-ray absorption spectra were collected at room temperature.

Data collected was processed using the Demeter software suite. EXAFS data was preprocessed by extracting the EXAFS oscillations $\chi(k)$ as a function of photoelectron wavenumber $k$ before fitting. The theoretical paths were generated using FEFF6 and the models were determined using the fitting program Artemis. ${ }^{6-8}$ The computational structure ${ }^{9}$ of the reported compound $\left[\mathrm{Co}(\mathrm{DIM}) \mathrm{Br}_{2}\right]^{+}$was used for fitting.

CoDIM-Monarch: Co-Functionalized Monarch Carbon Powder was prepared according to the methods described above. After functionalization, the carbon powder was finely ground with mortar and pestle. A Teflon washer (5.3 mm internal diameter) was sealed on one side with Kapton tape, and the powder was then transferred to the inside of this ring before compacting with a Teflon rod and sealing the remaining face with Kapton tape. 


\section{Surface Coverage Determination}

Catalyst surface site density was estimated by integrating the process in the cyclic voltammogram that is attributed to the bound species. Integration was bounded by a straight line connecting the two chosen potential values. Assuming one electron transferred per [CoDIM] unit, we calculated site densities of $\sim 0.80 \mathrm{nmol} \mathrm{cm}{ }^{-2}$ (flexible graphite) and $\sim 0.56 \mathrm{nmol} \mathrm{cm}{ }^{-2}$ (glassy carbon disk) using the equation $Q=n F A \Gamma_{0}+Q_{d l}$, where $\mathrm{Q}$ is the integrated charge, $\mathrm{n}$ is the number of electrons, $\mathrm{F}$ is Faraday's constant, $\mathrm{A}$ is the area of the electrode, $\Gamma_{0}$ is the surface coverage, and $\mathrm{Q}_{\mathrm{dl}}$ is the double layer charge.

\section{Tafel Data Collection}

Tafel plots were obtained via potentiostatic measurements on graphite-conjugated cobalt catalysts (GCC-CoDIM) in $0.5 \mathrm{M} \mathrm{Na}_{2} \mathrm{SO}_{4}$ electrolyte with $40 \mathrm{mM} \mathrm{NaNO}$. For each run, the current produced at a specified potential after $20 \mathrm{~s}$ of polarization was measured. Data were collected in $10 \mathrm{mV}$ increments between $-1.22 \mathrm{~V}$ and $-1.30 \mathrm{~V} v s$. SCE. Data were collected in succession for each potential step without an intervening pause. The Tafel plots were then normalized for the number of Co surface sites as measured by cyclic voltammetry.

\section{Calculation of Faradaic Efficiency}

The amount of ammonia produced by CPE at $-1.4 \mathrm{~V}$ vs. SCE was determined by the indophenol method. ${ }^{2}$ Solution for CPE at -1.4 V: $0.5 \mathrm{M} \mathrm{Na}_{2} \mathrm{SO}_{4}, 20 \mathrm{mM} \mathrm{NaNO}_{2}$ in $\mathrm{H}_{2} \mathrm{O}(30 \mathrm{~mL}), \mathrm{pH}=6.1$. Ammonia quantification shows $0.25 \mathrm{mmol} \mathrm{NH}_{3}$ produced over $2 \mathrm{~h} \mathrm{CPE}$. Final $\mathrm{pH}=12.8$. A control experiment with identical conditions but an unmodified (oxidized) electrode produced only $5.4 \mu \mathrm{mol} \mathrm{NH}$. According to equation 1, where $\mathrm{ne}^{-}$is the number of electrons in the process (six, as shown in equation 2), 


$$
\begin{gathered}
F E=\frac{\left(n e^{-}\right) F\left(\mathrm{~mol} \mathrm{NH}_{3}\right)}{Q} \\
\mathrm{NO}_{2}^{-}+7 \mathrm{H}^{+}+6 \mathrm{e}^{-} \rightarrow \mathrm{NH}_{3}+2 \mathrm{H}_{2} \mathrm{O}
\end{gathered}
$$

mol $\mathrm{NH}_{3}$ is the moles of ammonia produced in $\mathrm{CPE}$, and $\mathrm{Q}$ is the charge consumption, the Faradaic efficiency can be calculated as $99.5 \%$ after subtracting the background charge consumption and ammonia production from performing the same experiment with only an oxidized flexible graphite electrode. 


\section{Electrochemical Data}

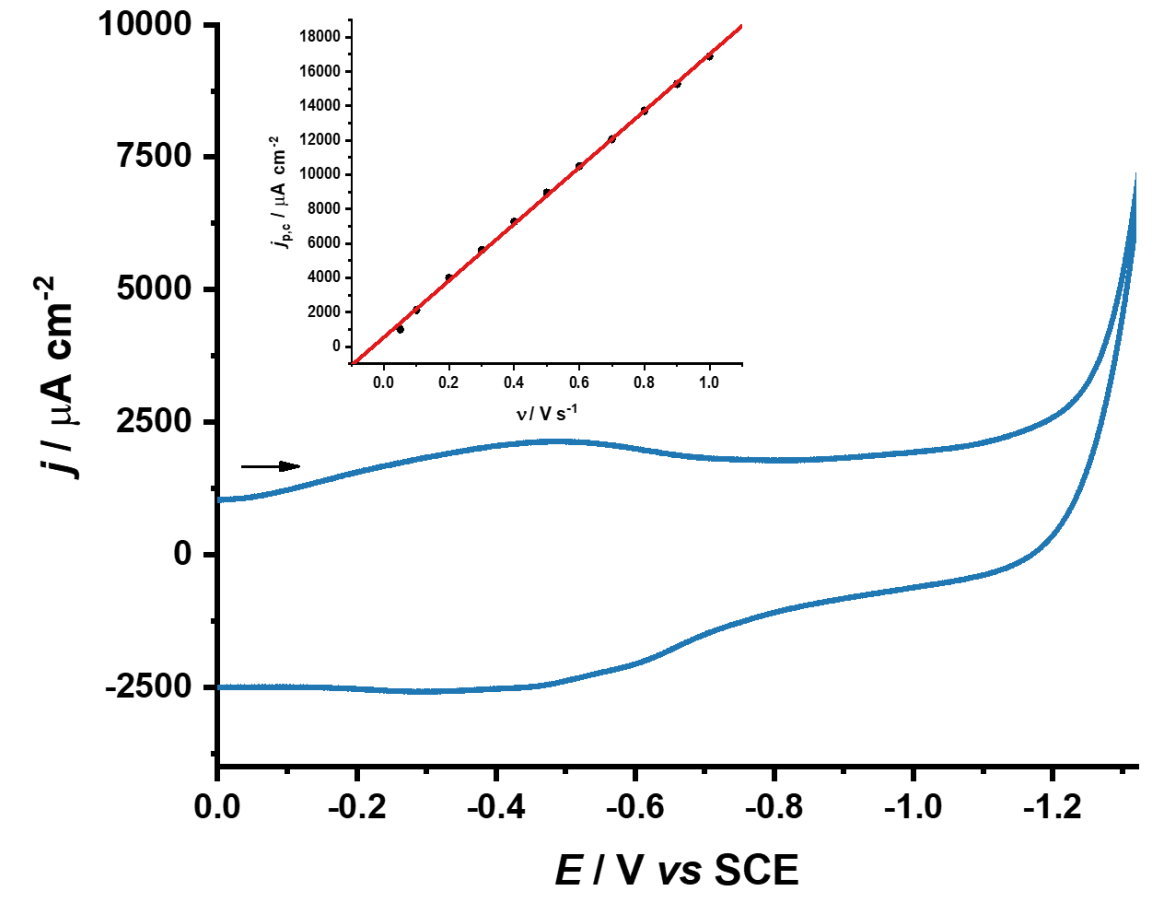

Figure S1: Cyclic voltammogram of GCC-CoDIM (glassy carbon) recorded in $0.5 \mathrm{M} \mathrm{Na}_{2} \mathrm{SO}_{4}$, scan rate $100 \mathrm{mV} / \mathrm{s}$. Inset: Plot of $i_{\mathrm{p}, \mathrm{c}} v s$. $v$ and the best fit. The plot fits to the equation: $\mathrm{y}=0.0165 \mathrm{x}$ $+5.513 \times 10^{-4}, \mathrm{R}^{2}=0.999$.

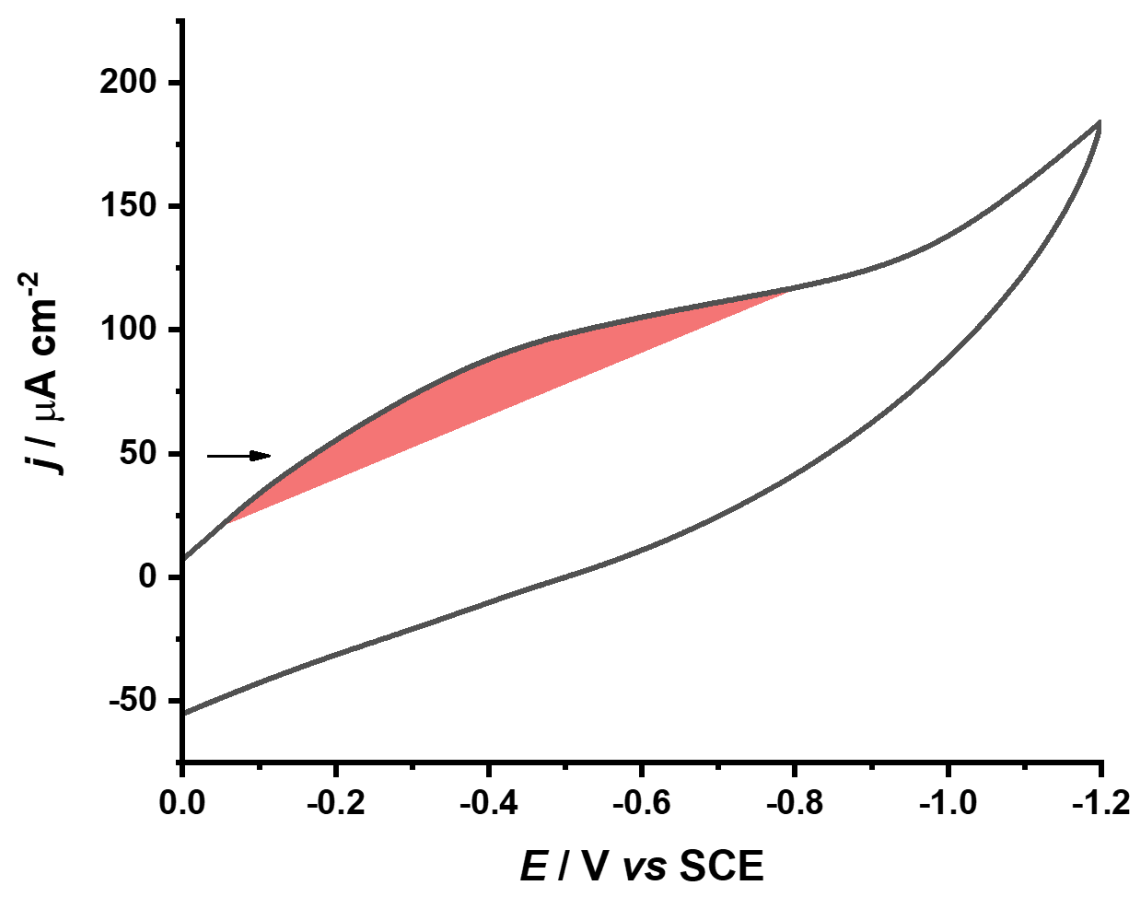

Figure S2: Cyclic voltammogram of CoDIM-FG (flexible graphite) recorded in $0.1 \mathrm{M} \mathrm{KBr}$, scan rate $100 \mathrm{mV} / \mathrm{s}$. Area of integration $=5.19 \times 10^{-4} \mathrm{C}$. Red shows area of integration. 


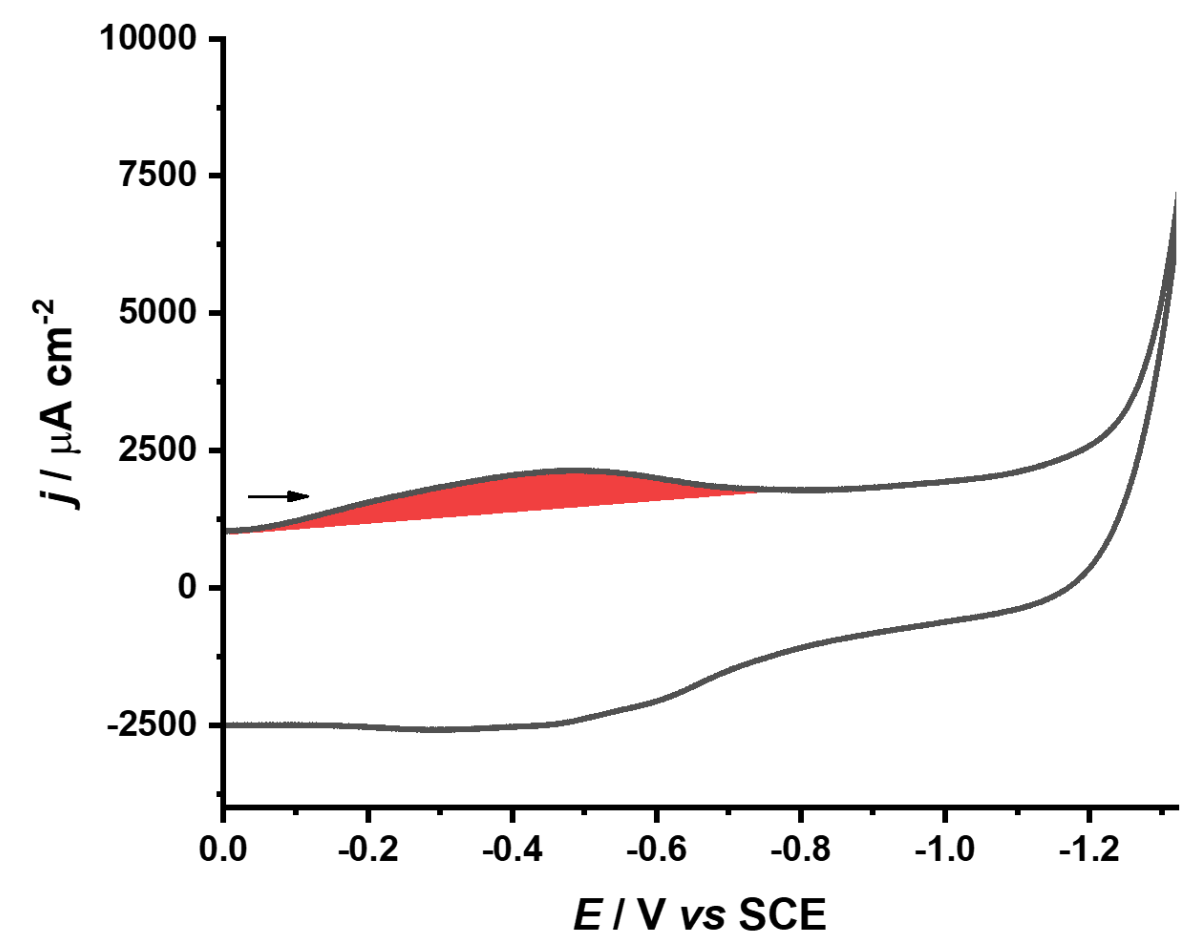

Figure S3: Cyclic voltammogram of GCC-CoDIM (glassy carbon) recorded in $0.5 \mathrm{M} \mathrm{Na}_{2} \mathrm{SO}_{4}$, scan rate $100 \mathrm{mV} / \mathrm{s}$. Area of integration $=3.92 \times 10^{-6} \mathrm{C}$. Red shows area of integration.

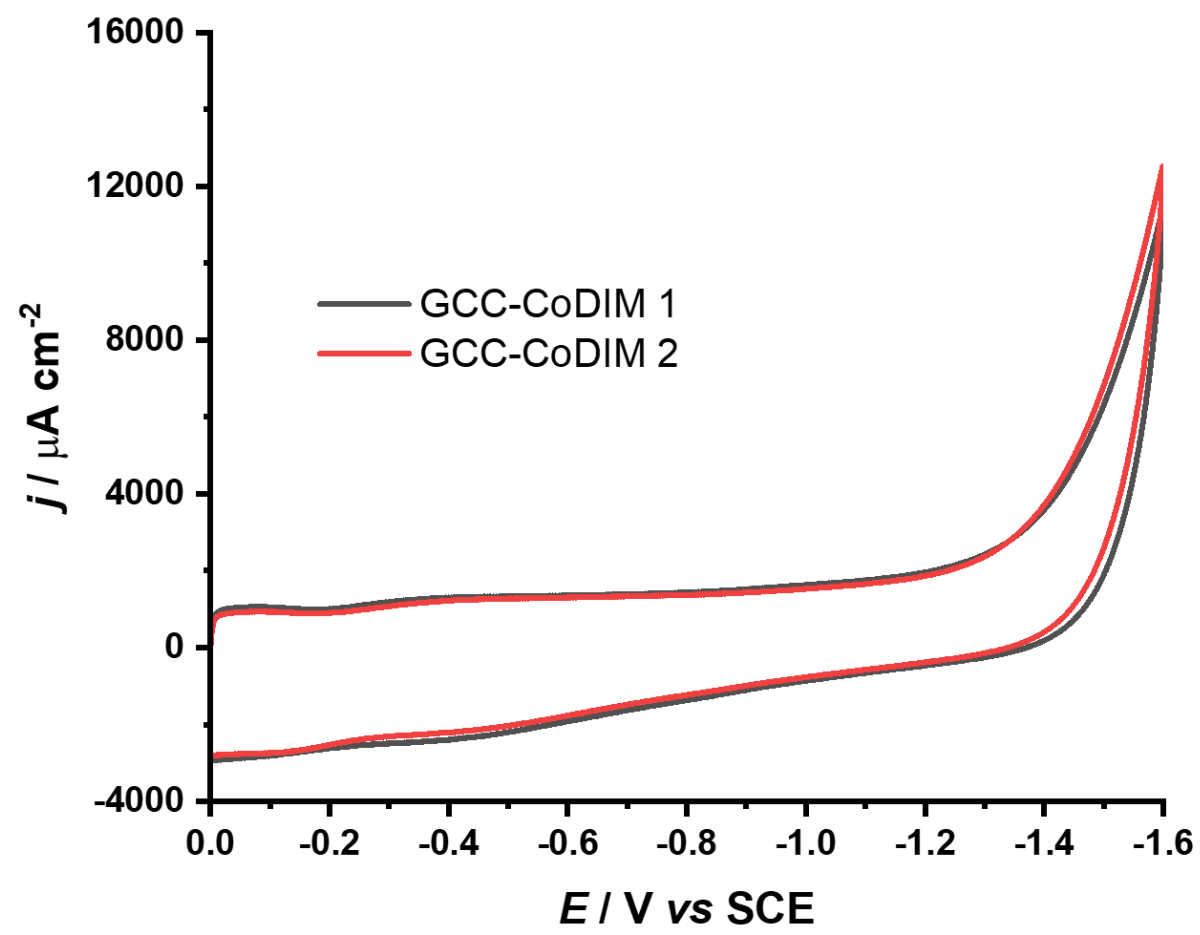

Figure S4: Cyclic voltammogram of two independently prepared GCC-CoDIM (glassy carbon) recorded in $0.5 \mathrm{M} \mathrm{Na}_{2} \mathrm{SO}_{4}$ with $40 \mathrm{mM} \mathrm{NaNO}_{2}$, scan rate $100 \mathrm{mV} / \mathrm{s}$. 


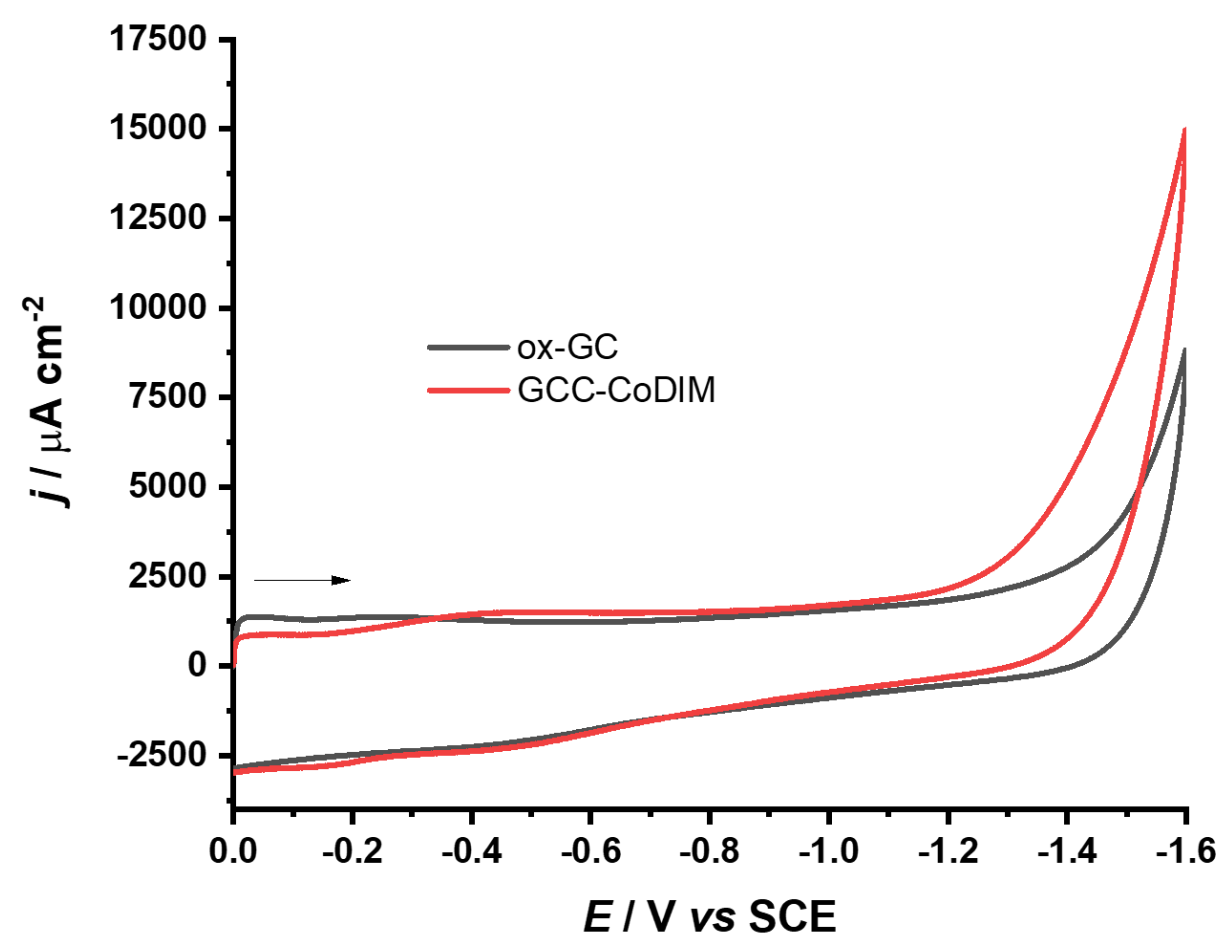

Figure S5: Cyclic voltammograms of GCC-CoDIM (glassy carbon) (red) and oxidized GC (black) recorded in $0.5 \mathrm{M} \mathrm{Na}_{2} \mathrm{SO}_{4}$ with $40 \mathrm{mM} \mathrm{NaNO}_{2}$, scan rate $100 \mathrm{mV} / \mathrm{s}$.

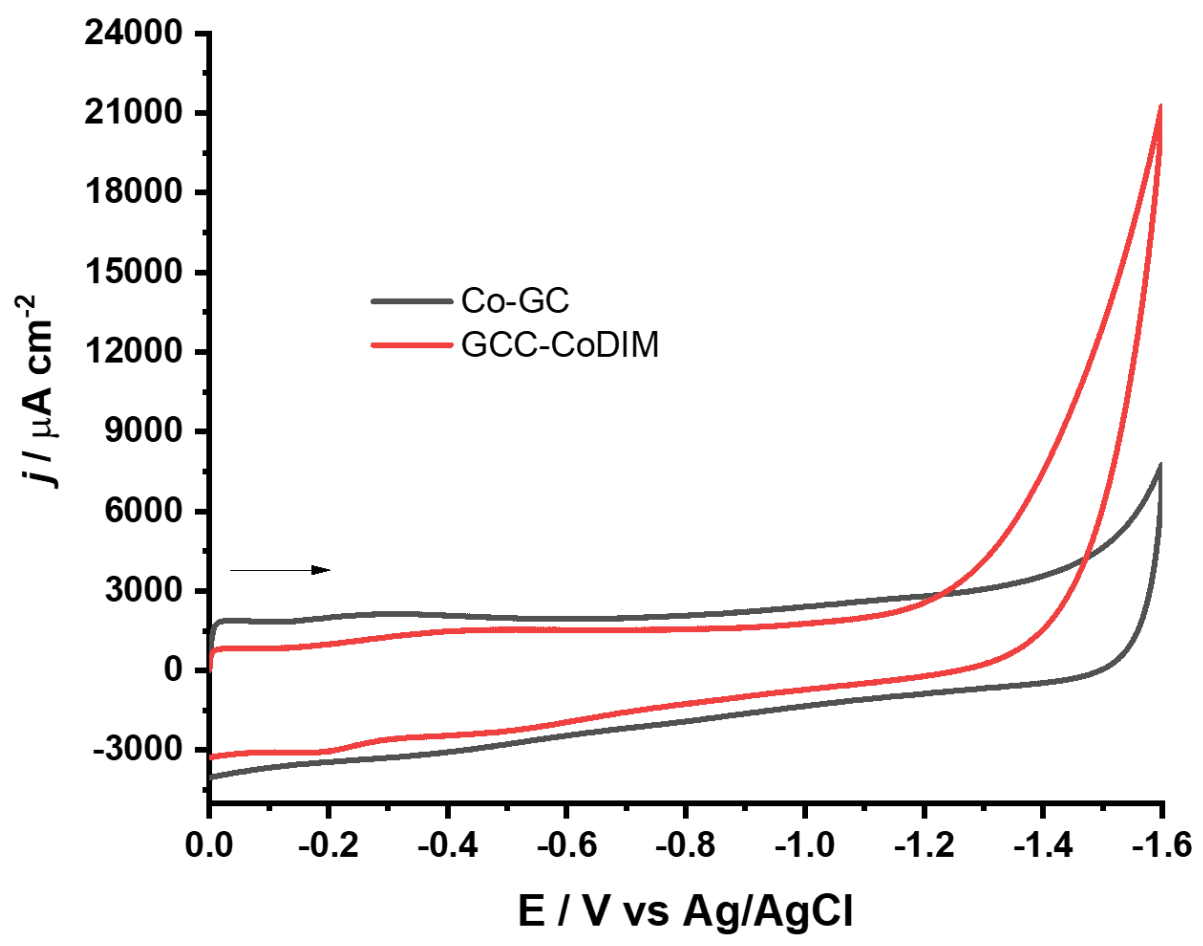

Figure S6: Cyclic voltammograms of GCC-CoDIM (glassy carbon) (red) and oxidized GC soaked in $\mathrm{CoBr}_{2} \cdot 6 \mathrm{H}_{2} \mathrm{O} /$ methanol solution (black) recorded in $0.5 \mathrm{M} \mathrm{Na}_{2} \mathrm{SO}_{4}$ with $40 \mathrm{mM} \mathrm{NaNO}_{2}$, scan rate $100 \mathrm{mV} / \mathrm{s}$. 


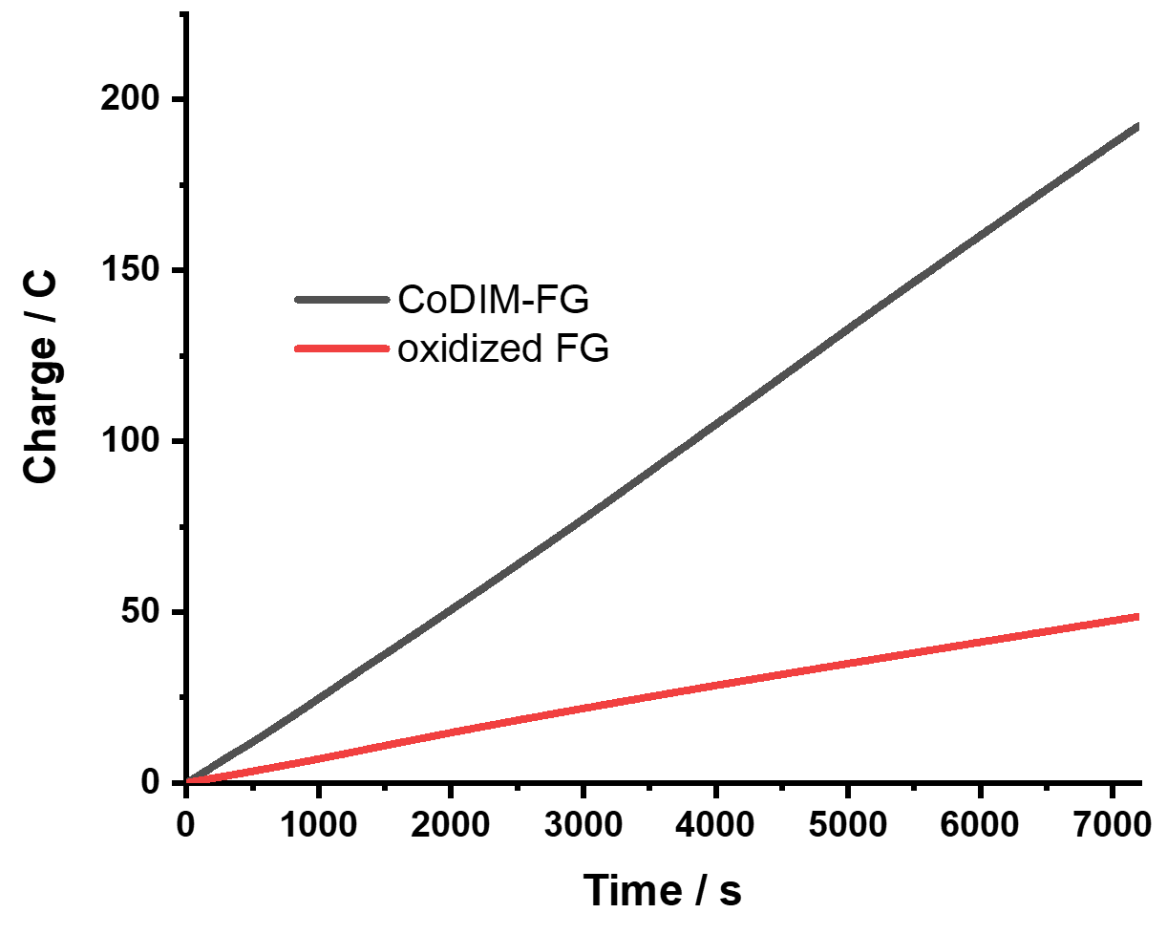

Figure S7: Charge passed during CPE with CoDIM-FG (black) or oxidized FG prefunctionalization (red) in $0.5 \mathrm{M} \mathrm{Na}_{2} \mathrm{SO}_{4}$ with $20 \mathrm{mM} \mathrm{NaNO}_{2}$ for 2 hours at $-1.4 \mathrm{~V} v s$. SCE.

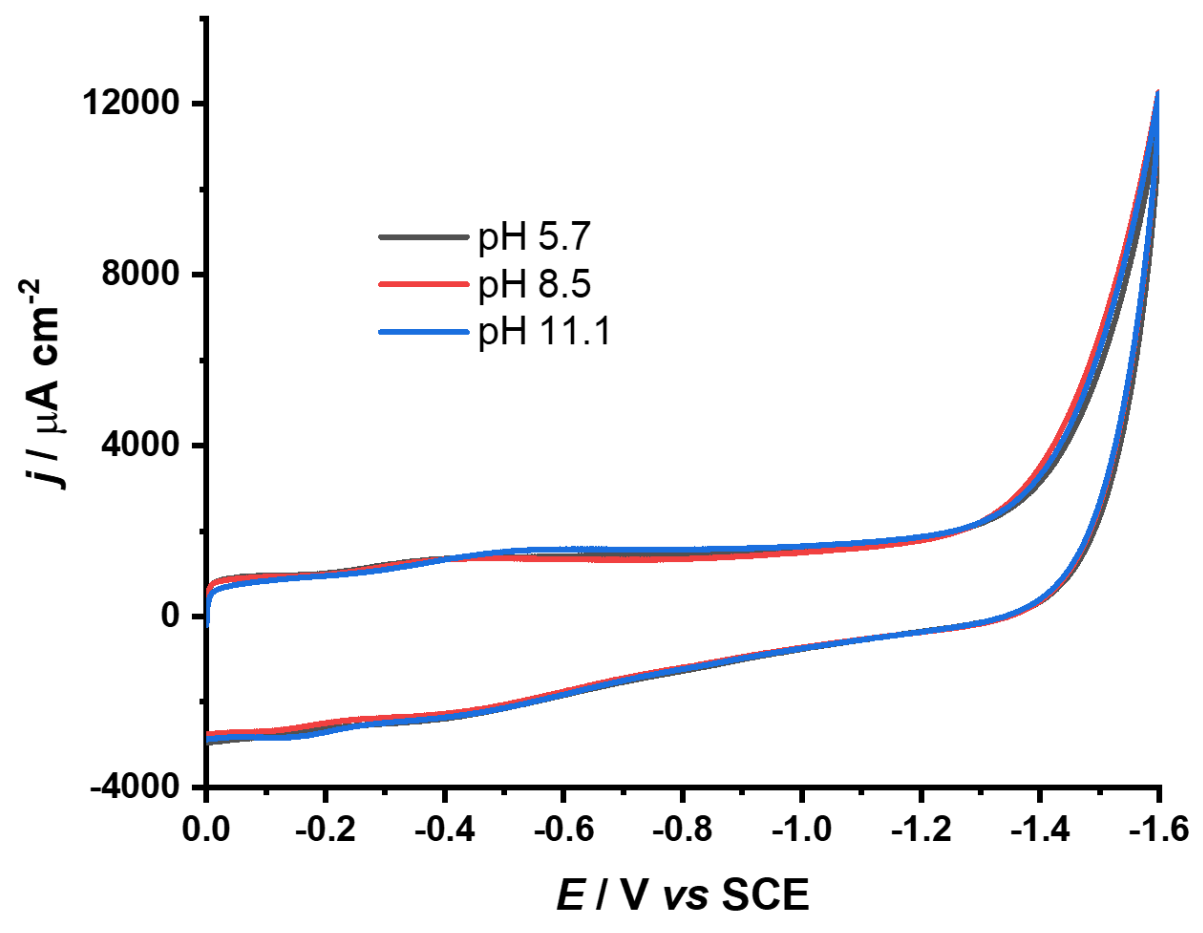

Figure S8: Cyclic voltammogram of GCC-CoDIM (glassy carbon) recorded in $0.5 \mathrm{M} \mathrm{Na}_{2} \mathrm{SO}_{4}$ with $20 \mathrm{mM} \mathrm{NaNO}_{2}$ at pH 5.7 (black), $\mathrm{pH} 8.5$ (red), and pH 11.1 (blue), scan rate $100 \mathrm{mV} / \mathrm{s}$. 


\section{X-Ray Absorption Spectroscopy Data}

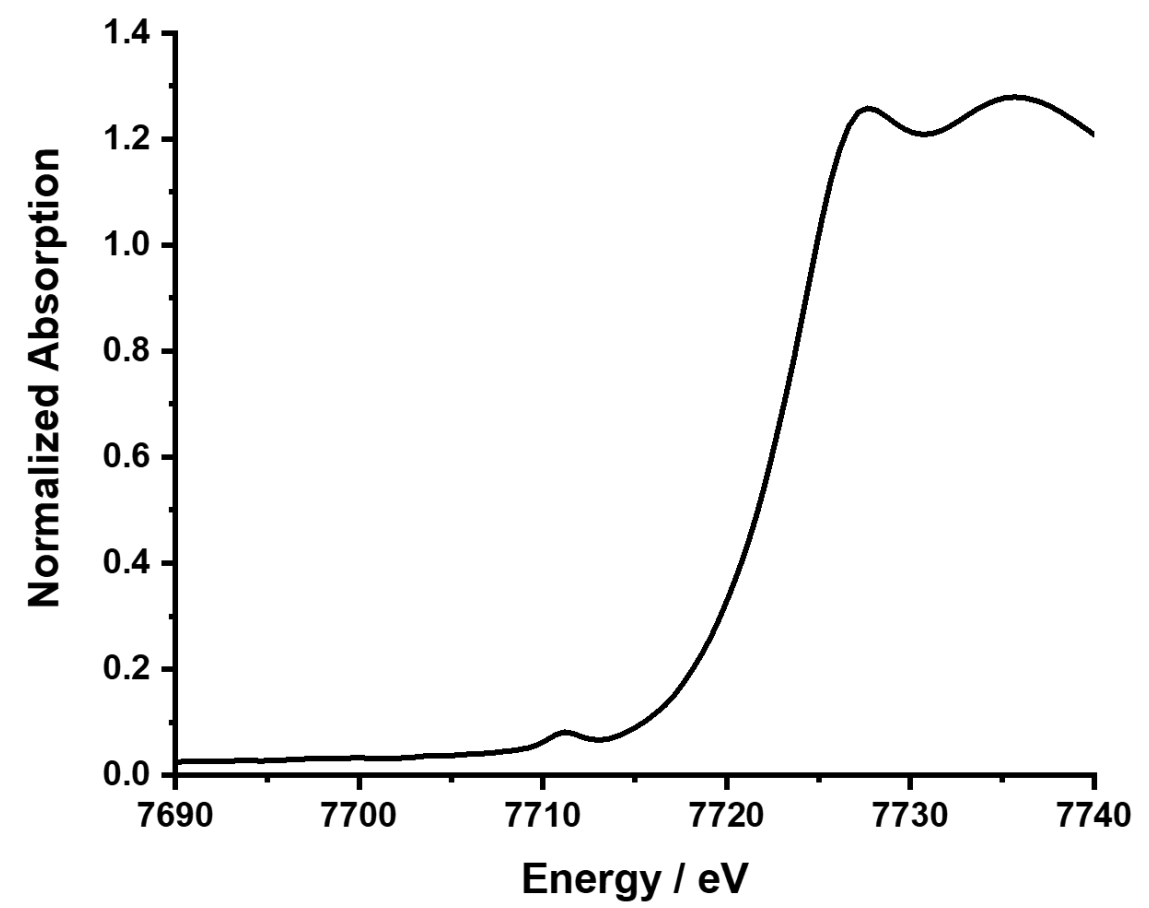

Figure 9: Normalized K-edge X-ray absorption near edge structure spectrum of CoDIMfunctionalized Monarch Carbon Powder.

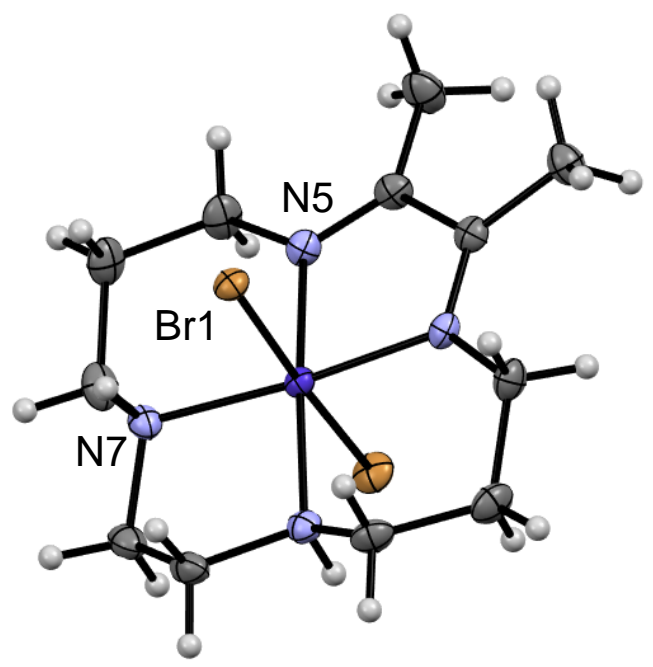

Figure S10: Crystal structure of $\left[\mathrm{Co}(\mathrm{DIM}) \mathrm{Br}_{2}\right]^{+}$with atom labels. ${ }^{9}$

Table S1: EXAFS Fit Parameters for CoDIM-functionalized Monarch Carbon Powder.

\begin{tabular}{llllll}
\hline Complex Co & $\mathrm{N}$ & $\mathrm{R}(\AA)$ & $\sigma^{2}\left(\AA^{2}\right)$ & R-factor & Reduced chi-square \\
\hline Co-N5 & 2 & $1.93(1)$ & $0.004(2)$ & 0.014 & 117.8 \\
Co-N7 & 2 & $1.98(1)$ & $0.004(2)$ & & \\
Co-Br1 & 2 & $2.39(4)$ & $0.022(6)$ & & \\
\hline$\Delta \mathrm{E}_{0}=0 \mathrm{eV} ; \mathrm{S}_{0}{ }^{2}=$ & 1.2; Independent Points: 10.6 ; Fitting Range: k: $1.5-10 \AA^{-1} ; \mathrm{R}: 1.0-3.0 \AA$
\end{tabular}


$\mathrm{N}$, Coordination numbers; R, interatomic distances; $\sigma^{2}$, Debye-Waller factors (the mean-square deviations in interatomic distance). The values in parentheses are the estimated standard deviations; $\Delta \mathrm{E}_{0}$, change in the photoelectron energy; $\mathrm{S}_{0}^{2}$, amplitude reduction factor.

Table S2: Comparison of EXAFS, single crystal XRD, and DFT-calculated bond lengths.

\begin{tabular}{lllll}
\hline Co-L bond & $\mathrm{N}$ & $\begin{array}{l}\text { DFT } \\
\text { model }(\AA)\end{array}$ & $\begin{array}{l}\text { EXAFS } \\
\mathrm{R}(\AA)\end{array}$ & $\begin{array}{l}\text { Crystal } \\
\text { structure }(\AA)^{9}\end{array}$ \\
\hline Co-N5 & 2 & 1.946 & $1.93(1)$ & $1.930(2)$ \\
Co-N7 & 2 & 1.993 & $1.98(1)$ & $1.975(2)$ \\
Co-Br1 & 2 & 2.460 & $2.39(4)$ & $2.4009(1)$ \\
\hline
\end{tabular}

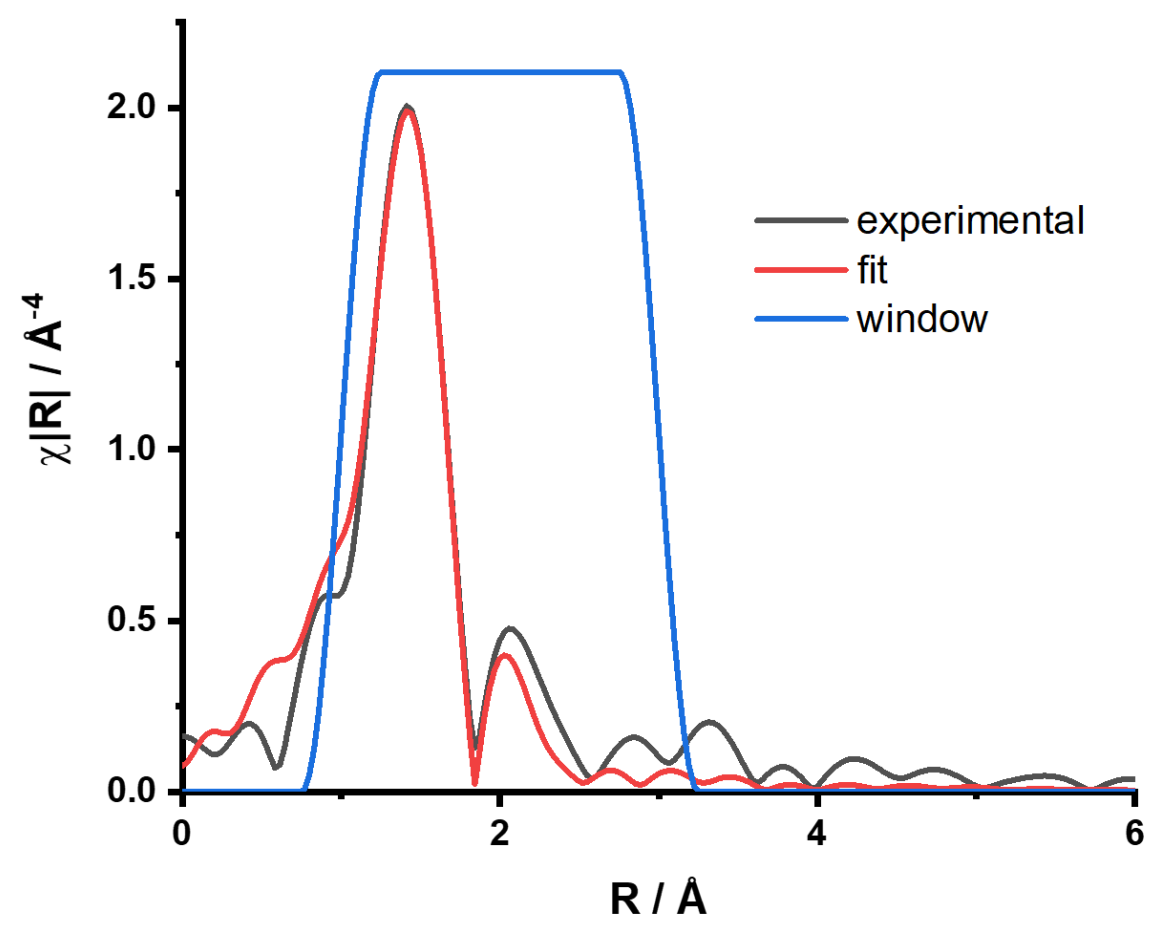

Figure S11: EXAFS spectrum (black) and fit (red) in R-space at the Co K-edge absorption of CoDIM-functionalized Monarch Carbon Powder. 


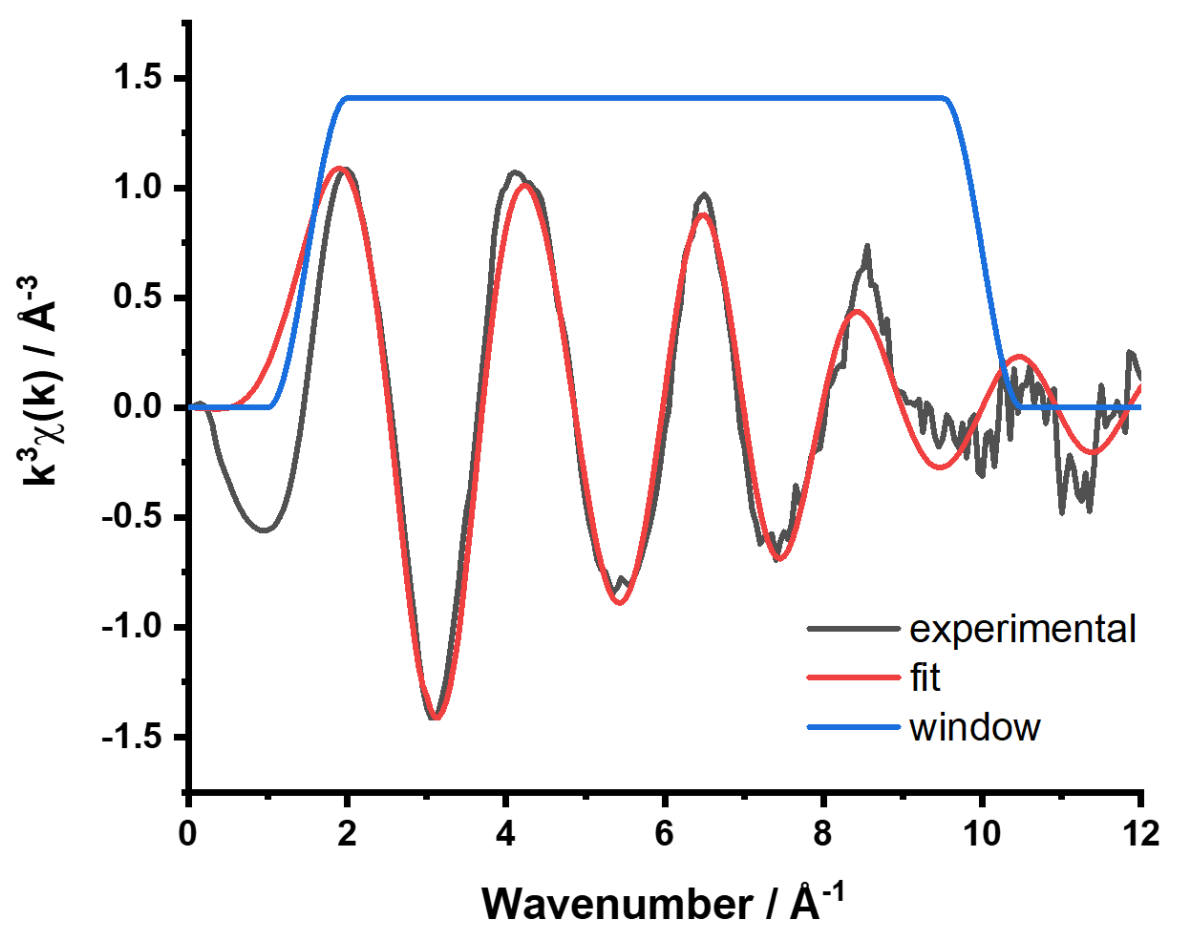

Figure S12: EXAFS spectrum (black) and fit (red) in k-space at the Co K-edge absorption of CoDIM-functionalized Monarch Carbon Powder. 


\section{X-Ray Photoelectron Spectroscopy Data}

Table S3: Surface atomic concentrations determined from XPS.

\begin{tabular}{|c|c|c|c|c|c|c|c|}
\hline Sample & Treatment & C \% & O \% & $\mathbf{N} \%$ & Co \% & Br \% & Cl \% \\
\hline GC & N/A & 97.5 & 2.3 & 0.2 & N/A & N/A & \\
\hline GC-ox & $\begin{array}{l}\text { Oxidized at } 3.3 \mathrm{~V} v s \\
\mathrm{SCE} \text { in } 0.1 \mathrm{M} \mathrm{H}_{2} \mathrm{SO}_{4}\end{array}$ & 69.1 & 29.4 & 1.6 & N/A & N/A & \\
\hline GCC-CoDIM & N/A (freshly prepared) & 71.1 & 21.5 & 6.3 & 0.8 & 0.3 & \\
\hline \multirow{3}{*}{ (glassy carbon) } & $1 \mathrm{~h}$ soak in $\mathrm{pH} 13 \mathrm{NaOH}$ & 68.3 & 20.6 & 9.7 & 0.8 & 0.6 & \\
\hline & $\begin{array}{c}\text { Potentiostatic } \\
\text { polarization at }-1.4 \mathrm{~V} \\
\text { vs. } \mathrm{SCE} \text { for } 2 \mathrm{~h} \text { with } 20 \\
\mathrm{mM} \mathrm{NaNO}_{2}\end{array}$ & 69.8 & 21.9 & 8.0 & 0.2 & 0.1 & \\
\hline & $12 \mathrm{~h}$ soak in $1.0 \mathrm{M} \mathrm{KCl}$ & 71.5 & 20.6 & 6.8 & 0.4 & 0.1 & 0.7 \\
\hline CoDIM-FG & $\begin{array}{c}\text { Potentiostatic } \\
\text { polarization at }-1.4 \mathrm{~V} \\
\text { vs. } \mathrm{SCE} \text { for } 2 \mathrm{~h} \text { with } 20 \\
\mathrm{mM} \mathrm{NaNO}_{2}\end{array}$ & & & 73.5 & 23.2 & 3.3 & \\
\hline $\begin{array}{l}\text { CoDIM- } \\
\text { Monarch }\end{array}$ & N/A (freshly prepared) & & & 79.1 & 20.4 & $0.5^{10}$ & \\
\hline
\end{tabular}

Table S4: Relative surface atomic concentrations of $\mathrm{Co}, \mathrm{N}, \mathrm{Br}$, and $\mathrm{Cl}$ in GCC-CoDIM determined from XPS. ${ }^{\mathrm{a}}$

\begin{tabular}{cccccc}
\hline Sample & Treatment & N \% & Co \% & Br \% & Cl \% \\
\hline GCC-CoDIM & N/A (freshly prepared) & 85.9 & 10.3 & 3.8 & \\
(glassy carbon) & 1 h soak in pH 13 NaOH & 87.7 & 7.3 & 5.0 & \\
& $\begin{array}{c}\text { Potentiostatic polarization } \\
\text { at }-1.4 \mathrm{~V} \text { vs. SCE for 2 h } \\
\text { with } 20 \mathrm{mM} \mathrm{NaNO}\end{array}$ & 96.0 & 2.7 & 1.3 & \\
& 12 h soak in 1.0 M KCl & 85.4 & 4.8 & 0.8 & 9.0 \\
\hline
\end{tabular}

${ }^{a}$ This is the same data as presented in Table S3, but with oxygen and carbon excluded from the atomic ratios. 
Excess $\mathrm{N}$ content in functionalized electrodes is attributed to the presence of non-macrocyclic imines that do not contain a metal center. This hypothesis is supported by the presence of a peak at $401.3 \mathrm{eV}$ in the N 1s high resolution XPS data (Figure S14 top), which is attributed to protonated nitrogens from these non-metallated imines after acid wash. Soaking the functionalized electrode in $\mathrm{pH} 13 \mathrm{NaOH}$ solution leads to the decrease of this peak at high binding energy to yield the spectrum shown in Figure S14, bottom. The peak at $401.3 \mathrm{eV}$ is still present but has decreased to $3 \%$ of the overall $\mathrm{N}$ content. The data in Figure S14, bottom can be fit with two peaks at 399.2 \& $399.9 \mathrm{eV}$ in a 1:1 ratio, corresponding to the imine and amine nitrogens, respectively.

$\mathrm{Br}$ content is observed to decrease with time under vacuum (Table S5), accounting for the unexpectedly small $\mathrm{Br} \%$ values in Table $\mathrm{S} 3$.

Table S5: Relative surface atomic concentrations of $\mathrm{Co}$ and $\mathrm{Br}$ in GCC-CoDIM after variable time under ultra-high vacuum determined from XPS.

\begin{tabular}{cccc}
\hline Sample & Time under ultra-high vacuum & Co \% & Br \% \\
\hline $\begin{array}{c}\text { GCC-CoDIM (glassy } \\
\text { carbon) }\end{array}$ & 4 hours & 87.6 & 12.4 \\
& 28 hours & 96.2 & 3.8
\end{tabular}

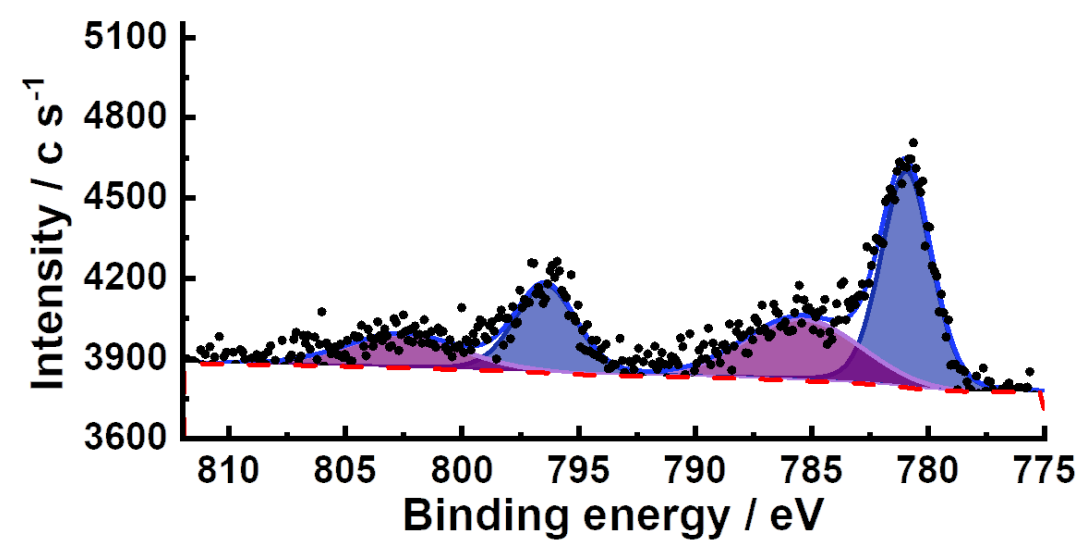

Figure S13: High-resolution Co 2p XPS spectrum of freshly prepared GCC-CoDIM (glassy carbon). The measured signal is in black, the overall fit manifold in blue, and the fit peaks in blue and purple. 


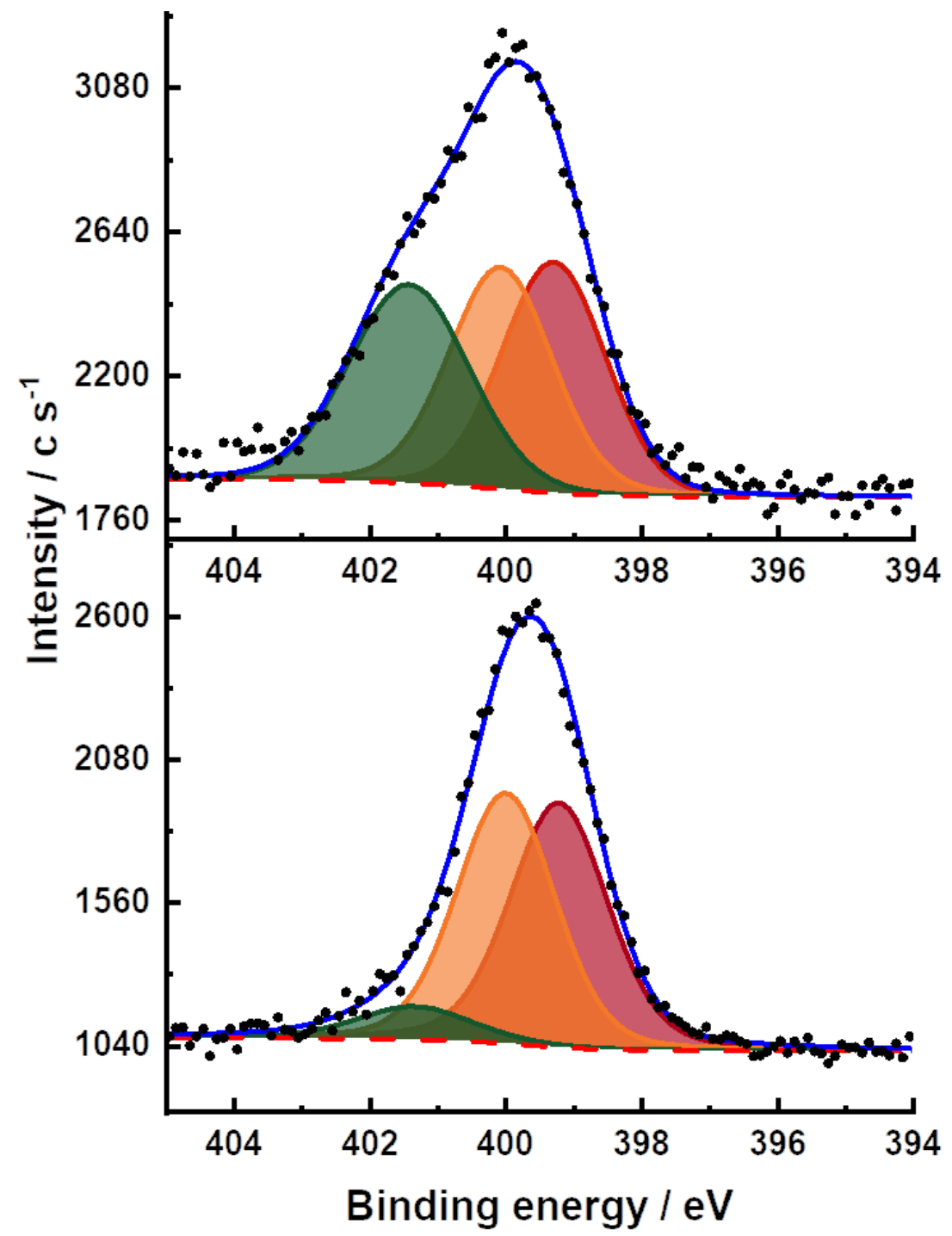

Figure S14: High-resolution N 1s XPS spectra of freshly prepared GCC-CoDIM (top) and GCCCoDIM after a soak in $\mathrm{pH} 13 \mathrm{NaOH}$ solution (bottom). The measured signal is in black, the fit background in dashed red, the fit peaks in green, orange, and red, and the overall fit manifold in blue. 


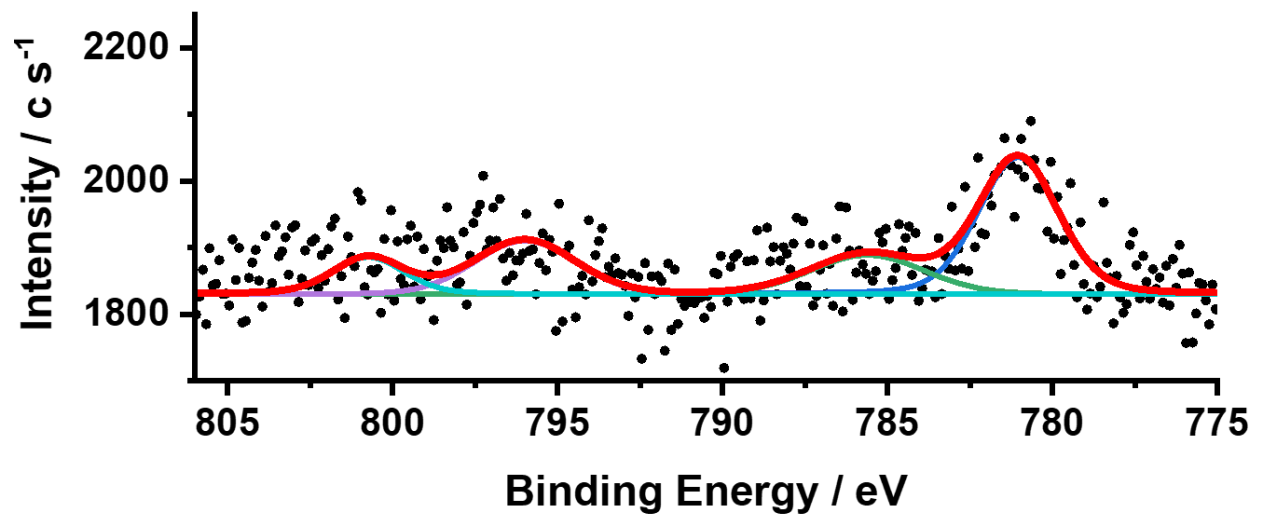

Figure S15: High-resolution Co 2p XPS spectrum of CoDIM-FG after $2 \mathrm{~h}$ bulk electrolysis at -1.4 $\mathrm{V} v s$. SCE. The measured signal is in black, the overall fit manifold in red, and the fit peaks in blue and green.

a) GCC-CoDIM

a) oxidized glassy carbon

- polished glassy carbon
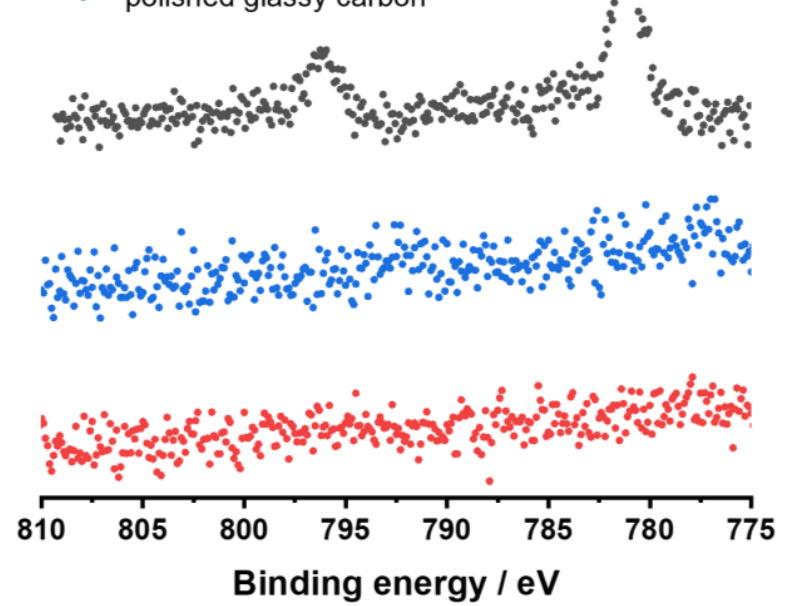

b)

$$
\begin{aligned}
& \text { GCC-CODIM } \\
& \text { oxidized glassy carbon } \quad: \\
& \text { polished glassy carbon }
\end{aligned}
$$

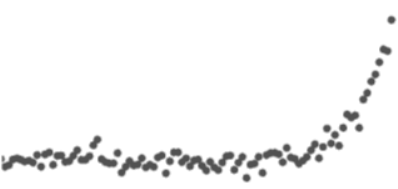

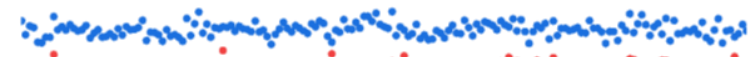

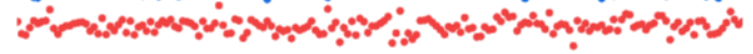

$\begin{array}{llllllllll}410 & 408 & 406 & 404 & 402 & 400 & 398 & 396 & 394 & 392\end{array}$

Binding energy / eV

Figure S16: a) High-resolution Co 2p XPS spectra of freshly prepared GCC-CoDIM (black), an oxidized glassy carbon electrode (blue), and a polished glassy carbon electrode (red). b) Highresolution N 1s XPS spectra of freshly prepared GCC-CoDIM (black), an oxidized glassy carbon electrode (blue), and a polished glassy carbon electrode (red). 
- after soaking in $\mathrm{KCl}$

- freshly prepared
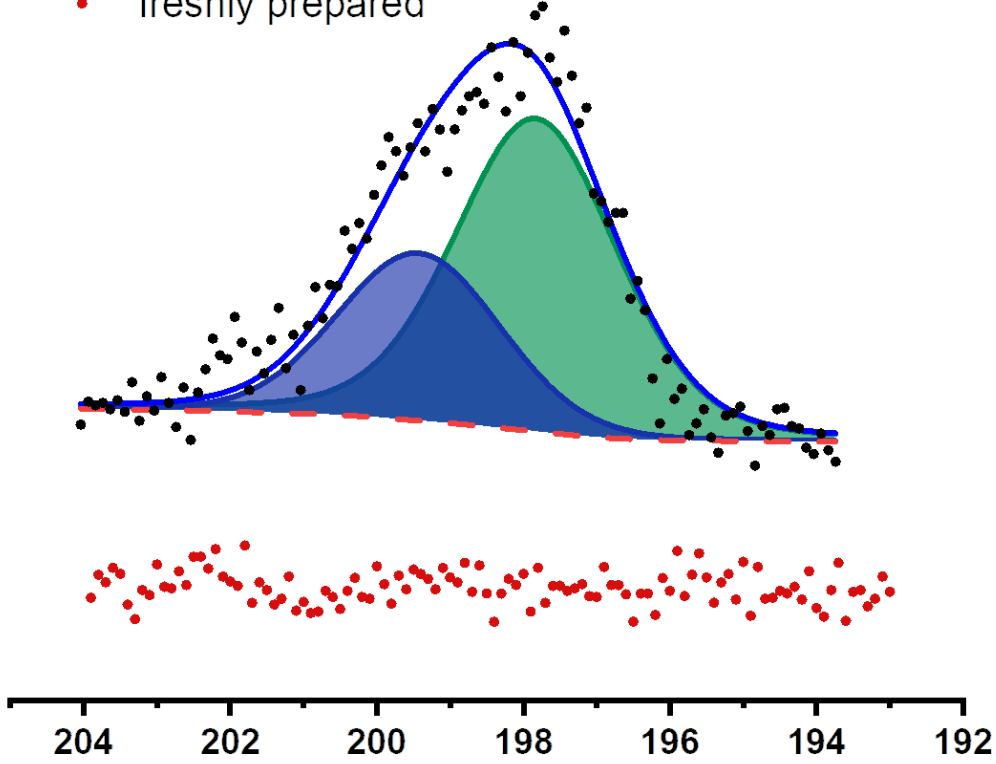

Figure S17: High-resolution Cl 2p XPS spectra of freshly prepared GCC-CoDIM (red) and GCCCoDIM after soaking 12 hours in $1.0 \mathrm{M} \mathrm{KCl}$ solution. The measured signal is in black, the overall fit manifold in blue, the fit background in dashed red, and the fit peaks in blue and green.
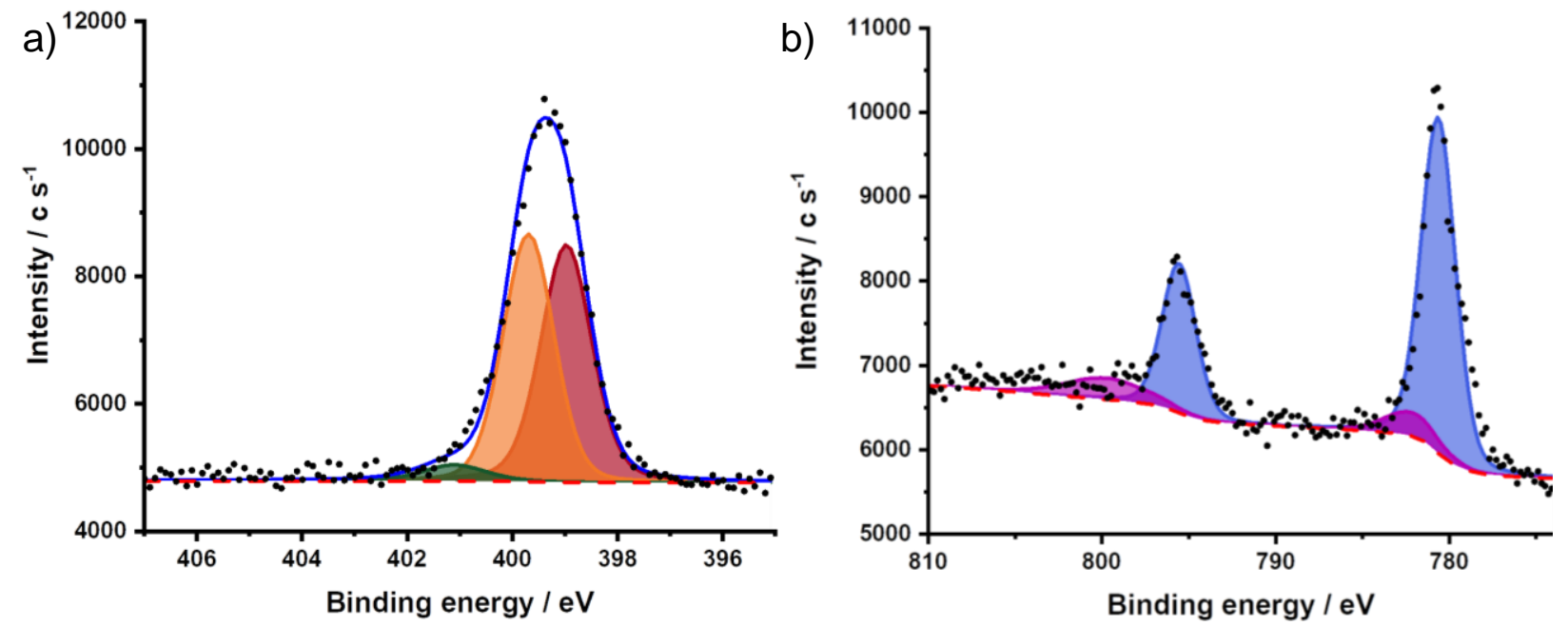

Figure S18: a) High-resolution N 1s XPS spectra of [Co(DIM)Br 2$] B r$. The measured signal is in black, the fit background in dashed red, the fit peaks in green, orange, and red, and the overall fit manifold in blue. b) High-resolution Co $2 p$ XPS spectrum of [Co(DIM) $\left.\mathrm{Br}_{2}\right] \mathrm{Br}$. The measured signal is in black, the overall fit manifold in blue, and the fit peaks in blue and purple. 
Table S6: Peak binding energies from high resolution $\mathrm{N} 1 \mathrm{~s}$ and Co $2 \mathrm{p}$ XPS data of $\left[\mathrm{Co}(\mathrm{DIM}) \mathrm{Br}_{2}\right] \mathrm{Br}$ and GCC-CoDIM.

\begin{tabular}{|c|c|c|c|}
\hline & N 1s & Co 2p $3 / 2$ & Co 2p $1 / 2$ \\
\hline$\left[\mathrm{Co}(\mathrm{DIM}) \mathrm{Br}_{2}\right] \mathrm{Br}$ & $399.0,399.9 \mathrm{eV}$ & $780.6 \mathrm{eV}$ & $795.6 \mathrm{eV}$ \\
\hline GCC-CoDIM & $399.2,399.9 \mathrm{eV}$ & $781.0 \mathrm{eV}$ & $796.4 \mathrm{eV}$ \\
\hline
\end{tabular}

\section{References}

1. Mathews, J. E.; George, S.; Mathews, P.; Mathai, E.; Brahmadathan, K. N.; Seshadri, L., The Griess Test: An Inexpensive Screening Test for Asymptomatic Bacteriuria in Pregnancy. Aust. New Zealand J. Obstet. Gynaecol. 1998, 38 (4), 407-410.

2. Weatherburn, M. W., Phenol-hypochlorite reaction for determination of ammonia. Anal. Chem. 1967, 39 (8), 971-974.

3. Quantification of Bromide by APHA 4500 Method: Phenol Red Colorimetric Method; Perkin Elmer, Inc.: 2015.

4. Oh, S.; Gallagher, J. R.; Miller, J. T.; Surendranath, Y., Graphite-Conjugated Rhenium Catalysts for Carbon Dioxide Reduction. J. Am. Chem. Soc. 2016, 138 (6), 1820-1823.

5. Jackels, S. C.; Farmery, K.; Barefield, E. K.; Rose, N. J.; Busch, D. H., Tetragonal cobalt(III) complexes containing tetradentate macrocyclic amine ligands with different degrees of unsaturation. Inorg. Chem. 1972, 11 (12), 2893-2901.

6. Eisenberger, P.; Kincaid, B., EXAFS: new horizons in structure determinations. Science 1978, 200 (4349), 1441-1447.

7. Newville, M., IFEFFIT : interactive XAFS analysis and FEFF fitting. J. Synchrotron Radiat. 2001, 8 (2), 322-324.

8. Rehr, J. J.; Albers, R. C., Theoretical approaches to X-ray absorption fine structure. Rev. Mod. Phys. 2000, 72 (3), 621-654.

9. $\quad \mathrm{Xu}, \mathrm{S}$.; Ashley, D. C.; Kwon, H.-Y.; Ware, G. R.; Chen, C.-H.; Losovyj, Y.; Gao, X.; Jakubikova, E.; Smith, J., A flexible, redox-active macrocycle enables the electrocatalytic reduction of nitrate to ammonia by a cobalt complex. Chem. Sci. 2018, 9 (22), 4950-4958.

10. Br content is hypothesized to be low due to the discussed loss of $\mathrm{Br}$ under ultra-high vacuum. ICP-MS results confirm that $\mathrm{Br}$ is present in the sample before exposure to UHV on the same order of magnitude as Co. 